\title{
Comparison of Mutagenic Activities of Various Ultra-Fine Particles
}

\author{
Chang Gyun Park', Hyun Ki Cho', Han Jae Shin'르, Ki Hong Park ${ }^{3}$ and Heung Bin Lim ${ }^{1}$ \\ ${ }^{1}$ College of Agriculture, Life \& Environment Sciences, Chungbuk National University, Cheongju, Korea \\ ${ }^{2} K T \& G$ Research Institute, Daejeon, Korea \\ ${ }^{3}$ National Leading Research Laboratory (Aerosol Technology and Monitoring Laboratory), School of Environmental \\ Science and Engineering, Gwangju Institute of Science and Technology (GIST), Gwangju, Korea
}

\begin{abstract}
Air pollution is increasing, along with consumption of fossil fuels such as coal and diesel gas. Air pollutants are known to be a major cause of respiratory-related illness and death, however, there are few reports on the genotoxic characterization of diverse air pollutants in Korea. In this study, we investigated the mutagenic activity of various particles such as diesel exhaust particles (DEP), combustion of rice straw (RSC), pine stem (PSC), and coal (CC), tunnel dust (TD), and road side dust (RD). Ultra-fine particles (UFPs) were collected by the glass fiber filter pad. Then, we performed a chemical analysis to see each of the component features of each particulate matter. The mutagenicity of various UFPs was determined by the Ames test with four Salmonella typhimurium strains with or without metabolic activation. The optimal concentrations of UFPs were selected based on result of a concentration decision test. Moreover, in order to compare relative mutagenicity among UFPs, we selected and tested DEP as mutation reference. DEP, RSC, and PSC induced concentration-dependent increases in revertant colony numbers with TA98, TA100, and TA1537 strains in the absence and presence of metabolic activation. DEP showed the highest specific activity among the particulate matters. In this study, we conclude that DEP, RSC, PSC, and TD displayed varying degrees of mutagenicity, and these results suggest that the mutagenicity of these air pollutants is associated with the presence of polycyclic aromatic hydrocarbons (PAHs) in these particulate matters.
\end{abstract}

Key words: Air pollution, Ultra-fine particle, Mutagenicity, Ames test

\section{INTRODUTCION}

Earth's atmosphere has been polluted as a result of continuing urbanization and industrialization. The generated byproducts (e.g., exhaust particles from automobiles, com- bustion particles, and heavy metals) have shown various negative effects in people and have seriously contaminated the air. Recently, air conditions in China are worsening because of industrialization, global warming, and air stagnation (1). Fine particles from vehicle exhaust and

\section{Correspondence to: Heung Bin Lim, Department of Industrial Crop Science and Technology, Chungbuk National University, Cheongju-si, Chungbuk 28644, Korea \\ E-mail: heungbin@chungbuk.ac.kr}

This is an Open-Access article distributed under the terms of the Creative Commons Attribution Non-Commercial License (http:// creativecommons.org/licenses/by-nc/3.0) which permits unrestricted non-commercial use, distribution, and reproduction in any medium, provided the original work is properly cited.
Abbreviation: DEP, Diesel exhaust particles; RSC, Combustion of rice straw; PSC, Combustion of pine stem; CC, Coal combustion; TD, Tunnel dust; RD, Road side dust; UFPs, Ultra-fine particles; PAHs, Polycyclic aromatic hydrocarbons; COPD, Chronic obstructive pulmonary disease; CVD, Cardiovascular disease; PMs, Particle matters; DMSO, Dimethyl sulfoxide; 2-AA, 2-Aminoanthracen; 4NQO, 4-Nitroquinoline-oxide; SA, Sodium azide; NIES, National institute for environmental studies; GIST, Gwangju institution science and technology; OC, Organic carbon; EC, Elemental carbon; IC, lon chromatography; ICP-MS, Inductively coupled plasma-mass spectrometer; KIT, Korea institute of toxicology; TPM, Total particulate matter; SD, Standard deviations; POM, Polycyclic organic matter; SAHs, Substituted aromatic hydrocarbons; HCAs, Heterocyclic aromatic compounds; SRM, Standard reference material. 
coal and biomass combustion, with diameters of less than $10 \mu \mathrm{M}$, are generally called PM10, and PM2.5 (particle with diameters less than $2.5 \mu \mathrm{M}$ ) called ultra-fine particles (UFPs). These UFPs are created by photochemical reactions between dust, metalloids, harmful substances, and products of combustion from factories or vehicles. UFPs usually consist of organic, and inorganic materials and ions $(2,3)$. UFPs are reported to be comprised of organic compounds $(50 \%)$, trace metal oxides $(14 \%)$, elemental carbon $(8.7 \%)$, and nitrate $(6.8 \%)$, in addition to catalytic metals such as $\mathrm{Fe}, \mathrm{Ti}, \mathrm{Cr}, \mathrm{Zn}$, and Ce. Therefore, UFPs have been pressing problems since our primitive society. Typically, particles larger than $10 \mu \mathrm{M}$ can be filter by the nose or throat, whereas those that are $2.5 \sim 10 \mu \mathrm{M}$ are removed by coughing or spitting. Smaller particles (less than $2.5 \mu \mathrm{M}$ ), can easily penetrate the deepest alveolar regions of the lung. PM2.5 represent almost $60 \%$ of all fine particles, and even when the UFPs are water-soluble, they can reach alveolar-capillaries directly $(4,5)$. Due to these factors, fine dust causes directly adverse effects to humans, the rate of asthma, chronic obstructive pulmonary disease (COPD), cardiovascular disease (CVD), and lung cancer are increasing in our society, especially, rate of the above diseases are higher in cities, which have higher levels of particulate matters than those in the country $(6,7)$.

So, the health adverse effects of particle matters (PMs) and UFPs which are directly effect in our body are focused on the pulmonary toxicity and mutagenicity (8-10). From among these, toxicity of UFPs have been important, for determining their effects on DNA. Many studies have been reported in which many PMs showed mutagenicity and actually affects DNA. DEP (11), Biomass (12), Coal combustion (13), and Dust (14) have been reported with mutagenicity, and these toxicity reasons have been associated with the existences of nitroarenes, aromatic amines, and polycyclic aromatic hydrocarbons (PAHs). However, even with same type of PMs, the constituents and their toxicities are changed depending on the environment and external conditions (15-17). Thus, we cannot determine the toxicity about one type of PMs as a representative standard, toxicity data on PMs according to various types and conditions are required. Indeed, most of the previous studies have evaluated only PMs, and measurements as UFP are limited or still insufficient in types.

In this study, we collected five UFPs (RSC, PSC, CC, $\mathrm{TD}$, and RD) among PMs which be generated and influence directly or indirectly around us, and a revertant mutagenicity assay (Ames test) was conducted for determining a possibility of potential carcinogenicities of the five UFPs. Ames test is a reversion mutation experiment, it has the advantage that it can be easily carried out at relatively low cost and within a short period of time and it is widely used in initial genotoxicity screening experiments $(18,19)$.
Also, in order to compare relative mutagenicity among UFPs, we selected and tested DEP as mutation reference. Through this study, we measured the carcinogenicities of UFPs that could be exposed around us, and compared in order to inform people the dangerousness and seriousness of UFPs.

\section{MATERIALS AND METHODS}

Reagents. Dimethyl sulfoxide (DMSO), 2-aminoanthracen (2AA), 4-nitroquinoline-oxide (4NQO), sodium azide (SA), agar, glucose, histidine/biotin, oxoid nutrient broth no.2, and $\mathrm{NaCl}$ were purchased from Sigma-Aldrich Company (Bellefonte, PA, USA). The S9 fraction of rat liver and co-factors for the NADH regenerating system were purchased from Mol-Tox (Boone, NC, USA) and Wako (Osaka, Japan). All other chemicals and the used reagents were of high-performance liquid chromatography.

Collection of UFPs. All PMs were collected on glass fiber filters and stored in desiccator. Before collection, filters had been kept for more than $24 \mathrm{hr}$ in a desiccator and then weighed, and after collection, filters were again kept for more than $24 \mathrm{hr}$ in a desiccator and weighed. The masses of the collected particles were calculated as the difference between the pre-collection and collection weights. The collected filters were extracted with DMSO at 250 rpm and room temperature for $60 \mathrm{~min}$, and then used for mutagenicity test after filtering with a syringe filter (glass microfiber membrane, $1.2 \mu \mathrm{M}$ ). We purchased DEP from the National Institute for Environmental Studies (NIES), Japan. DEP was collected from exhaust particulates, using fiber glass filters, from car with a 4JB1 type 2,740 cc fourcylinder direct-injection diesel engine at $1,500 \mathrm{rpm}$ and, 10 torque $(10 \mathrm{~kg} / \mathrm{m})$. Flaming coal and bituminous coal were obtained from the Ha-dong thermoelectric power plant, Republic of Korea. We operated a solid aerosol generator in 20.67 22 L per minute (LPM) flow conditions for generating aerosol-type of coal powder. The coal powders were inserted at a speed $3.6 \mathrm{~g} / \mathrm{hr}$ and were heated to $1,100^{\circ} \mathrm{C}$ furnace (a drop tube furnace with a quartz tube, Lindberg/Blue M, Model HTF55342C, Thermo Electron Corp, USA). After cooling system, CC particles less than $2.5 \mu \mathrm{M}$ were selectively trapped using a Cyclone (URG2000-30EG, URG Corporation, NC, USA) and vacuum pump at a flow rate of 16.7 LPM. To collect RSC and PSC, we used a biomass system machine created by Gwangju Institution Science and Technology (GIST) for sample collection of these materials, Republic of Korea. Twenty-five grams of RSC or PSC was placed in the combustion chamber and burned by torch for 1 2 min. After this, the samples were collected selectively less than $2.5 \mu \mathrm{M}$ particles by using Cyclone (URG-2000-30EG, URG corporation) and vacuum pump a flow rate of 16.7 LPM. We gathered 
the RD (in Unamdong Gwangju) from heavy traffic with measurement network and TD (in Biadong Gwangju) from center of a city by broom and dustpan. Then, these samples were filtered progressively by sieves with diameters of $1.7 \mathrm{mM}$ and $38 \mu \mathrm{M}$. As the result of filtering, we could gather particulate matters each less than diameter of $38 \mu \mathrm{M}$ particles. To get less than diameter of $2.5 \mu \mathrm{M}$ particles selectively, we used a solid aerosol generator (SAG410, TOPAS-GMBH, DRS, Germany) for regenerating 24.5 LPM and exploited Cyclone (URG-2000-30EG, URG corporation), vacuum pump in condition of 16.7 LPM.

Chemical analysis. The chemical analysis, was conducted using a PTFE membrane filter (Zeflour, pore size: $2.0 \mu \mathrm{M}$, diameter: $47 \mathrm{mM}$, Pall Corporation, Ann Arbor, MI, USA). In addition, organic carbon (OC)/elemental carbon (EC) or OC speciation analyses were conducted using a quartz filter that was equipped with a carbon denuder. We performed a chemical analysis to identify each compounds in collected UFPs. To determine OC and EC contents, we used a quartz filter that was baked at $450^{\circ} \mathrm{C}$ for analysis of $\mathrm{OC}, \mathrm{EC}$, and $\mathrm{OC}$ speciation, sample filters were subjected to a carbon denuder to remove the gas phase. OC, EC and total PAHs of DEP referred to the McDonald et al (19). Lastly, for ion analysis, we performed ion chromatography (850 Professional IC, Metrohm, St. Gallen, Switzerland), to analyze metals by inductively coupled plasma-mass spectrometer (ICP-MS, Waters, Milford, MA, USA) after sample filtering.

Mutagenicity assay. The Salmonella typhimurium test strains used in this study were kindly provided by the Korea Institute of Toxicology (KIT). We used strains TA98 and TA1537 to search for frame-shift mutations and strains TA100 and TA1535 to search for nucleotide substitutions. Before using these strains in tests, we checked for the genotypic characteristics of each strains (the histidine requirement, uvrB mutation, R-factor, rfa mutations, and spontaneous mutations). Then we could use the strains in the test. Mutagenicity was evaluated in S. typhimurium strains according to the method described by Maron and Ames (17). We used four strains to search for mutations in response to particulate matters. According to applicate with metabolic activation (S9 mix) or not, the test materials were subjected to direct plate incorporation. DMSO was added to an agar plate as a negative control substance. The optimal concentration of each sample for testing was determined by a concentration decision test. We dispensed $2 \mathrm{~mL}$ of the top agar sterilized in high pressure steam into a sterilized tube at $45^{\circ} \mathrm{C}$. And $100 \mu \mathrm{L}$ of test sample which was dissolved with DMSO to various concentration, $100 \mu \mathrm{L}$ of cultured strain and $500 \mu \mathrm{L}$ of $\mathrm{S} 9$ mix or $0.2 \mathrm{M}$ sodium phosphate buffer ( $\mathrm{pH} 7.4$ ) compounded at the tube. Then, the compounded tube was vor- texed for 2 3 sec and was smeared minimal glucose agar plate properly. When the plate had become hard, we closed a cover of the plate and overturned the plate. After culturing plates for $48 \mathrm{hr}$ in an incubator at $37^{\circ} \mathrm{C}$, we counted the number of revertant colonies in each plate.

Concentration decision test. To determine the proper concentrations for testing, a prepared stock solution was $10 \mathrm{mg} / \mathrm{mL}$ with DMSO because of limitations in the total particulate matter (TPM) from each of the extracted UFPs. For this reason, we set the maximum concentration for this test at $1 \mathrm{mg} /$ plate. After the test, when reverse mutation colonies were reproducible, and twice the number colonies observed comparing with negative controls, then we considered the plate positive for a mutation. If the background lawn was diminished compared to those in the negative controls, this was evidence of severe toxicity. Based on these results, we established the optimal concentrations.

Statistical analysis. Data obtained from the experiments are presented as means \pm standard deviations (SD) of at least three replicates. A one-way analysis of variance was conducted to compare the results obtained from testing each type of particulate matters. Student's $t$-test was performed for the statistical analysis of differences, with $p$ values less than 0.01 and 0.001 considered significant.

\section{RESULTS}

Chemical analysis. Results of the particulate matters analysis are shown in Table 1. The particulate matters filtrated in glass fiber filter were used for an analysis of chemical characteristics, including inorganic ions, organic carbons, elemental carbons, and other element contents. Through the chemical analysis, we could see each of the component features of each particulate matter. When the OC and EC contents expressed by $\mu \mathrm{g} / \mathrm{m}^{3}$ were compared, PSC had the most EC $\left(8,587 \mu \mathrm{g} / \mathrm{m}^{3}\right)$ and, RSC had most OC $\left(41,548 \mu \mathrm{g} / \mathrm{m}^{3}\right)$, followed by PSC $\left(28,566 \mu \mathrm{g} / \mathrm{m}^{3}\right)$. Other UFPs had not many amount of EC and OC against with DEP, RSC, and PSC. In case of ion contents, CC showed highest contents $(382.3 \mu \mathrm{g} / \mathrm{mg})$, followed by TD $(71.1 \mu \mathrm{g} / \mathrm{mg}), \operatorname{RSC}(63.2 \mu \mathrm{g} / \mathrm{mg})$, DEP $(29.0 \mu \mathrm{g} / \mathrm{mg})$, PSC $(26.8 \mu \mathrm{g} / \mathrm{mg})$, and RD $(23.4 \mu \mathrm{g} / \mathrm{mg})$. The PSC had the most total PAH contents $\left(652.6 \mu \mathrm{g} / \mathrm{m}^{3}\right)$. To compare relative contents of PAHs, which are known as major mutagenicity compounds, we calculated the percentage of PAH per OC (PAH/OC) and found that DEP had the highest percent compared with all tested other UFPs (9.4\%). Lastly, in the metals, CC had the most contents $(109.1 \mu \mathrm{g} /$ $\mathrm{mg})$, followed by TD $(69.4 \mu \mathrm{g} / \mathrm{mg}), \mathrm{RD}(25.2 \mu \mathrm{g} / \mathrm{mg})$, DEP $(9.6 \mu \mathrm{g} / \mathrm{mg})$, PSC $(0.7 \mu \mathrm{g} / \mathrm{mg})$, and RSC $(0.6 \mu \mathrm{g} / \mathrm{mg})$. As a result of component analysis, RSC, and PSC had rel- 
Table 1. Analysis of particulate matters

\begin{tabular}{lcccccc}
\hline \hline Analytes $^{\mathrm{a}}$ & DEP & RSC & PSC & CC & TD & RD \\
\hline Element carbon $\left(\mu \mathrm{g} / \mathrm{m}^{3}\right)$ & $557.1^{\mathrm{b}}$ & 1392 & 8587 & $1.5^{\mathrm{c}}$ & 0.57 & 1.37 \\
Organic carbon $\left(\mu \mathrm{g} / \mathrm{m}^{3}\right)$ & $192.9^{\mathrm{b}}$ & 41548 & 28566 & 50 & 5.33 & 3.44 \\
Ions $(\mu \mathrm{g} / \mathrm{mg})$ & 29.0 & 63.2 & 26.8 & 382.3 & 71.1 & 23.4 \\
\hline Total PAHs $\left(\mu \mathrm{g} / \mathrm{m}^{3}\right)$ & $18.1^{\mathrm{b}}$ & 170.2 & 652.6 & $127^{\mathrm{c}}$ & $8.2^{\mathrm{c}}$ & $4.7^{\mathrm{c}}$ \\
Total PAHs $/ \mathrm{OC}(\%)$ & 9.38 & 0.41 & 2.28 & 0.25 & 0.15 & 0.14 \\
\hline Metals $(\mu \mathrm{g} / \mathrm{mg})$ & 9.6 & 0.6 & 0.7 & 109.1 & 69.4 & 25.2 \\
\hline
\end{tabular}

aDEP: diesel exhaust particles, RSC: rice straw combustion, PSC: pine stem combustion, CC: coal combustion, TD: tunnel dust, RD: road side dust, ${ }^{\text {} T h e ~ P H A s ~ c o n c e n t r a t i o n ~ o n ~ D E P ~ w a s ~ m e a s u r e d ~ b y ~ M c D o n a l d ~ e t ~ a l . ~(19), ~ ' C o n c e n t r a t i o n ~ u n i t ~ o f ~ n g / m ~}{ }^{3}$ NA: Not analyzed.

atively large amounts of OC and EC and total PAHs. In the case of TD and RD containing coal, it showed low content of OC, EC, and PAHs, but showed features with relatively more metals contents than others.

Concentration decision test. In the concentration decision test, it was determined reasonable particulate matter concentrations with showing mutagenicity in the TA98
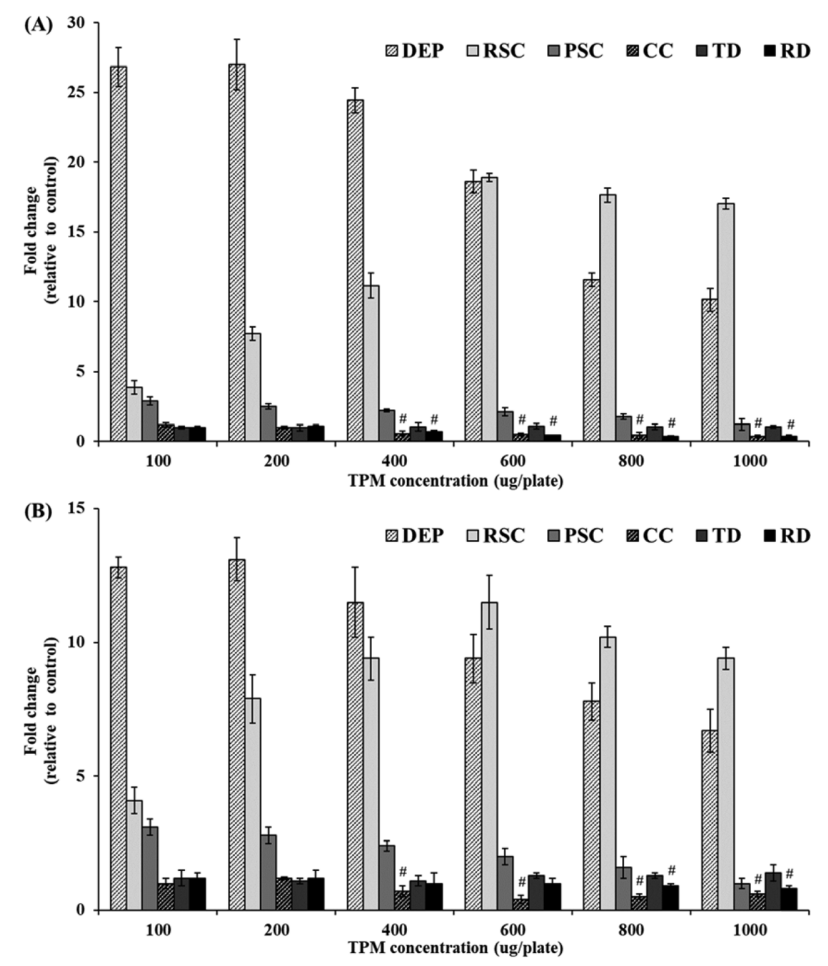

Fig. 1. The concentration decision results of DEP and UFPs in Ames test with TA98 strain. (A) Mutagenic response of TA98 strain in absence of metabolic activation, (B) mutagenic response of TA98 strain in metabolic activation. " The fold change values are less than 1.0 (negative control). DEP: diesel exhaust particles, RSC: rice straw combustion, PSC: pine stem combustion, CC: coal combustion, TD: tunnel dust, RD: road side dust. The fold change is calculated as a relative numerical value, with the particulate matters-exposed colony numbers divided by that of the negative control. strain, with or without metabolic activation (Fig. 1). This test was conducted using three plates per each of concentrations, and there were not any contaminants on the plates, determined by examining the maximum concentration and axenic culture with the S9 mix. Metabolic activation ( $\mathrm{S} 9 \mathrm{mix}$ ) in this test was confirmed using 2-aminoantracene (2-AA) as a positive control material that showed remarkable mutagenicity for TA98 strain.

Different numbers of revertant colonies were observed for the test particulate matters up to $1,000 \mu \mathrm{g} / \mathrm{plate}$ which was a maximum concentration. The test results were calculated as a relative numerical value, with the particulate matters-exposed colony numbers divided by that of the negative control. In this test, DEP showed a high fold change values from the initial concentration (100 $\mu \mathrm{g} / \mathrm{plate})$ without and with metabolic activation enzyme system, but the increased fold change was decreased from $400 \mu \mathrm{g} /$ plate concentrations. Thus, the DEP was tested again for searching appropriate mutagenic concentration, finally, $10 \mu \mathrm{g} /$ plate of DEP was optimal fold change value than $100 \mu \mathrm{g} /$ plate (data not shown). In case of RSC, the concentration-dependent response was observed up to $600 \mu \mathrm{g} /$ plate concentrations. However, the increased fold changes were decreased after $600 \mu \mathrm{g} /$ plate regardless of the S9 mix. PSC also showed that the highest fold change at $100 \mu \mathrm{g} /$ plate, the fold change was on the decline after $100 \mu \mathrm{g} /$ plate concentration regardless of the S9 mix. CC did not show any mutagenicity, but the revertant colonies were decreased in comparison with negative control from 400 $\mu \mathrm{g} /$ plate concentration regardless of the S9 mix. In case of $\mathrm{TD}$, did not appear special tendency such as increase or decrease in revertant colonies up to maximum concentration. Lastly, RD showed similar tendency with $\mathrm{CC}$ over $400 \mu \mathrm{g} /$ plate concentrations in absence of metabolic activation. In metabolic activation, $\mathrm{RD}$ did not show increasing fold changes up to $600 \mu \mathrm{g} /$ plate concentration, the fold change was decreased at over $800 \mu \mathrm{g} /$ plate concentrations.

The initial concentrations which increase revertant colony numbers by DEP and UFPs and maximum concentrations which show the highest revertant colony numbers by DEP and UFPs were calculated through this test. Therefore, the proper concentrations were selected, the optimal 
concentrations were the following: DEP $(0 \sim 10 \mu \mathrm{g} / \mathrm{plate})$, RSC (0 600 $\mu \mathrm{g} /$ plate), PSC $(0 \sim 100 \mu \mathrm{g} /$ plate $), C C(0 \sim 200$ $\mu \mathrm{g} /$ plate $)$, TD $(0 \sim 1,000 \mu \mathrm{g} /$ plate $)$, and $\mathrm{RD}(0 \sim 300 \mu \mathrm{g} /$ plate $)$.

Mutagenicity of UFPs. The mutagenicity of particulate matters was determined via an Ames incorporation assay (20). The positive control materials were 4NQO, SA (without S9 mix), and 2-AA (with S9 mix), and four strains, were used to estimate mutagenicity (Table 2, 3). Results without metabolic activation are shown in Table 2, result of metabolic activation in the mutant colony (mean \pm SD) are shown in Table 3. Mutagenicity was calculated as a relative numerical value, with the particulate mattersexposed colony numbers divided by that of the negative control. Among the particulate matters, DEP increased colony numbers in a concentration-dependent manner up to $10 \mu \mathrm{g} /$ plate, regardless of whether the $\mathrm{S} 9$ mix was present. The maximum number of revertant colony was 29.6 times more than the number of spontaneous revertants in strain TA98 without the S9 mix. Even it was shown higher the number of colony than positive control. And also DEP increased colony numbers at TA98 strain more than TA100 strain with or without S9 mix. This result was similar with the results of Shin et al (21). RSC was shown to the increase of revertant colony up to the maximum concentration, without regard for metabolic activation, except in strain TA1535 without S9 mix. The highest fold change was 18.9 times that observed in TA98 strain without the S9 mix. Except for TA1535 strain, RSC showed higher relative numerical values without $\mathrm{S} 9$ mix than with $\mathrm{S} 9$ mix at all strains. Particularly, at TA100 strain, RSC appeared higher increased colony numbers than DEP from $200 \mu \mathrm{g} /$ plate concentration. In case of PSC, without S9 mix, there was a dose dependent increase response up to $100 \mu \mathrm{g} /$ plate in strains TA100 and TA98. In the presence of the S9 mix, activity was similar to that without the S9 mix in strains TA98, TA100, also TA1535, and TA1537 showed the mutated colony number at each of maximum concentrations. The highest fold change was 3.1 times that observed in TA98 with the $\mathrm{S} 9$ mix. CC did not show a dose response

Table 2. Mutagenic response of Salmonella tester strains following exposure to ultra-fine particles in absence of metabolic activation

\begin{tabular}{|c|c|c|c|c|c|}
\hline \multirow{2}{*}{$\begin{array}{l}\text { Ultra-fine } \\
\text { particle }^{\mathrm{b}}\end{array}$} & \multirow{2}{*}{$\begin{array}{l}\text { Dose } \\
(\mu \mathrm{g} / \text { plate })\end{array}$} & \multicolumn{4}{|c|}{ Tester strain (mean revertants/plate [Factor] $]^{a}$ ) } \\
\hline & & TA100 & TA1535 & TA98 & TA1537 \\
\hline \multirow[t]{3}{*}{ DEP } & 0 & $124 \pm 22$ & $6 \pm 2$ & $26 \pm 6$ & $6 \pm 2$ \\
\hline & 1 & $177 \pm 11[1.4]$ & $14 \pm 2[2.2]$ & $141 \pm 22 * *[5.4]$ & $22 \pm 6^{*}[3.5]$ \\
\hline & 10 & $594 \pm 10^{* *}[4.8]$ & $24 \pm 5 *[3.8]$ & $771 \pm 92 * *[29.6]$ & $131 \pm 7 * *[20.7]$ \\
\hline \multirow[t]{3}{*}{ RSC } & 0 & $124 \pm 22$ & $6 \pm 2$ & $26 \pm 6$ & $6 \pm 2$ \\
\hline & 200 & $764 \pm 19 * *[6.4]$ & $10 \pm 2[1.6]$ & $216 \pm 14^{* *}[8.3]$ & $22 \pm 5^{*}[3.5]$ \\
\hline & 600 & $1500 \pm 32 * *[12.0]$ & $9 \pm 2[1.4]$ & $491 \pm 38 * *[18.9]$ & $53 \pm 10 * *[8.4]$ \\
\hline \multirow[t]{3}{*}{ PSC } & 0 & $124 \pm 22$ & $6 \pm 2$ & $26 \pm 6$ & $6 \pm 2$ \\
\hline & 50 & $253 \pm 14 *[2.0]$ & $8 \pm 2[1.3]$ & $58 \pm 8^{*}[2.2]$ & $13 \pm 3[2.0]$ \\
\hline & 100 & $315 \pm 18^{* *}[2.5]$ & $10 \pm 2[1.6]$ & $74 \pm 6^{* *}[2.9]$ & $13 \pm 2[2.0]$ \\
\hline \multirow[t]{3}{*}{$\mathrm{CC}$} & 0 & $124 \pm 22$ & $6 \pm 2$ & $26 \pm 6$ & $6 \pm 2$ \\
\hline & 100 & $130 \pm 14[1.0]$ & $8 \pm 1[1.7]$ & $32 \pm 11[1.2]$ & $7 \pm 1[1.0]$ \\
\hline & 200 & $136 \pm 1[1.1]$ & $9 \pm 3[1.2]$ & $26 \pm 5[1.0]$ & $9 \pm 1[1.4]$ \\
\hline \multirow[t]{3}{*}{ TD } & 0 & $124 \pm 22$ & $6 \pm 2$ & $26 \pm 6$ & $6 \pm 2$ \\
\hline & 500 & $158 \pm 8[1.3]$ & $11 \pm 1[1.8]$ & $27 \pm 3[1.0]$ & $16 \pm 6[2.5]$ \\
\hline & 1000 & $149 \pm 15[1.2]$ & $12 \pm 4[2.0]$ & $26 \pm 2[1.0]$ & $32 \pm 11^{*}[5.0]$ \\
\hline \multirow[t]{3}{*}{$\mathrm{RD}$} & 0 & $124 \pm 22$ & $6 \pm 2$ & $26 \pm 6$ & $6 \pm 2$ \\
\hline & 150 & $122 \pm 19[1.0]$ & $9 \pm 1[1.4]$ & $30 \pm 9[1.2]$ & $10 \pm 7[1.5]$ \\
\hline & 300 & $125 \pm 21[1.0]$ & $8 \pm 6[1.3]$ & $22 \pm 2[0.8]$ & $9 \pm 2[1.4]$ \\
\hline
\end{tabular}

Positive controls (SA: Sodiumazide, 4NQO: 4-Nitroquinoline-1-oxide)

$\begin{array}{llr}\text { TA } 100 & \text { SA }(1.0) & 1411 \pm 53^{* *}[11.3] \\ \text { TA } 1535 & \text { SA }(1.0) & 560 \pm 40^{* *}[88.5] \\ \text { TA } 98 & \text { 4NQO }(1.0) & 547 \pm 73^{* *}[22.5] \\ \text { TA } 1537 & \text { SA }(1.0) & 352 \pm 31^{* *}[55.6] \\ \text { TA } 102 & \text { 4NQO }(1.0) & 689 \pm 154^{*}[2.7]\end{array}$

${ }^{\mathrm{a} N o}$ of revertants of treated plate/No. of revertants of negative control plate.

${ }^{\mathrm{b}}$ Refer to Table 1 values are means \pm standard deviations.

* Significantly different from negative control plate group $(p<0.01)$.

** Significantly different from negative control plate group $(p<0.001)$. 
Table 3. Mutagenic response of Salmonella tester strains following exposure to ultra-fine particles in metabolic activation

\begin{tabular}{|c|c|c|c|c|c|}
\hline \multirow{2}{*}{$\begin{array}{l}\text { Ultra-fine } \\
\text { particle }^{b}\end{array}$} & \multirow{2}{*}{$\begin{array}{l}\text { Dose } \\
(\mu \mathrm{g} / \text { plate })\end{array}$} & \multicolumn{4}{|c|}{ Tester strain (mean revertants/plate $[\text { Factor }]^{\mathrm{a}}$ ) } \\
\hline & & TA100 & TA1535 & TA98 & TA1537 \\
\hline \multirow[t]{3}{*}{ DEP } & 0 & $161 \pm 12$ & $6 \pm 1$ & $35 \pm 6$ & $13 \pm 4$ \\
\hline & 1 & $166 \pm 15[1.0]$ & $14 \pm 1 *[2.2]$ & $84 \pm 8 *[2.4]$ & $28 \pm 7[2.2]$ \\
\hline & 10 & $427 \pm 27^{* *}[2.6]$ & $22 \pm 4 *[3.7]$ & $474 \pm 25 * *[13.4]$ & $105 \pm 8 * *[8.1]$ \\
\hline \multirow[t]{3}{*}{ RSC } & 0 & $161 \pm 12$ & $6 \pm 1$ & $35 \pm 6$ & $13 \pm 4$ \\
\hline & 200 & $392 \pm 17 * *[2.4]$ & $12 \pm 4$ [1.9] & $280 \pm 36^{* *}[7.9]$ & $50 \pm 5^{* *}[3.8]$ \\
\hline & 600 & $723 \pm 23^{* *}[4.5]$ & $16 \pm 7 *[2.7]$ & $408 \pm 34 * *[11.5]$ & $65 \pm 0 * *[5.0]$ \\
\hline \multirow[t]{3}{*}{ PSC } & 0 & $161 \pm 12$ & $6 \pm 1$ & $35 \pm 6$ & $13 \pm 4$ \\
\hline & 50 & $153 \pm 17[0.9]$ & $13 \pm 4[2.2]$ & $67 \pm 15[1.9]$ & $30 \pm 6[2.3]$ \\
\hline & 100 & $236 \pm 22 *[1.5]$ & $15 \pm 0 *[2.5]$ & $111 \pm 3 *[3.1]$ & $38 \pm 13$ [2.9] \\
\hline \multirow[t]{3}{*}{$\mathrm{CC}$} & 0 & $161 \pm 12$ & $6 \pm 1$ & $35 \pm 6$ & $13 \pm 4$ \\
\hline & 100 & $121 \pm 26[0.8]$ & $10 \pm 2[1.2]$ & $37 \pm 6[1.0]$ & $20 \pm 5[1.5]$ \\
\hline & 200 & $112 \pm 1[0.7]$ & $8 \pm 2[1.4]$ & $41 \pm 9[1.2]$ & $21 \pm 6[1.6]$ \\
\hline \multirow[t]{3}{*}{ TD } & 0 & $161 \pm 12$ & $6 \pm 1$ & $35 \pm 6$ & $13 \pm 4$ \\
\hline & 500 & $136 \pm 33[0.8]$ & $20 \pm 5^{*}[3.3]$ & $48 \pm 4[1.4]$ & $29 \pm 5 *[2.2]$ \\
\hline & 1000 & $143 \pm 2[0.9]$ & $24 \pm 2 * *[4.0]$ & $48 \pm 7[1.4]$ & $35 \pm 4 *[2.7]$ \\
\hline \multirow[t]{3}{*}{$\mathrm{RD}$} & 0 & $161 \pm 12$ & $6 \pm 1$ & $35 \pm 6$ & $13 \pm 4$ \\
\hline & 150 & $136 \pm 9[0.8]$ & $8 \pm 1[1.4]$ & $46 \pm 3[1.3]$ & $18 \pm 4[1.4]$ \\
\hline & 300 & $124 \pm 11[0.8]$ & $10 \pm 2[1.7]$ & $46 \pm 8[1.3]$ & $21 \pm 11[1.6]$ \\
\hline \multicolumn{6}{|c|}{ Positive controls (2-AA: 2-Aminoanthracene) } \\
\hline TA 100 & \multicolumn{2}{|c|}{$2 \mathrm{AA}(4.0)$} & \multicolumn{2}{|c|}{$2092 \pm 84 * *[13.0]$} & \\
\hline TA 1535 & \multicolumn{2}{|c|}{$2 \mathrm{AA}(4.0)$} & \multicolumn{2}{|c|}{$185 \pm 23 * *[30.8]$} & \\
\hline TA 98 & \multicolumn{2}{|c|}{$2 \mathrm{AA}(2.0)$} & \multicolumn{2}{|c|}{$1658 \pm 188 * *[36.0]$} & \\
\hline TA 1537 & \multicolumn{2}{|c|}{$2 \mathrm{AA}(4.0)$} & \multicolumn{2}{|c|}{$228 \pm 21 * *[17.5]$} & \\
\hline TA 102 & \multicolumn{2}{|c|}{ 2AA (4.0) } & \multicolumn{2}{|c|}{$1795 \pm 111 *[4.7]$} & \\
\hline
\end{tabular}

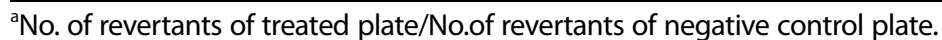

${ }^{\mathrm{b}}$ Refer to Table 1 values are means \pm standard deviations.

* Significantly different from negative control plate group $(p<0.01)$.

** Significantly different from negative control plate group $(p<0.001)$.

in any strain until the maximum concentration was applied. In the case of $\mathrm{TD}$, a linear concentration-response in the reverse mutation colony numbers was observed up to $1,000 \mu \mathrm{g} /$ plate with the $\mathrm{S} 9 \mathrm{mix}$ in strains TA1535 and TA1537. But the highest fold change was 5.0 times that observed in TA1537 which showed mutation colony numbers at $1,000 \mu \mathrm{g} /$ plate without the $\mathrm{S} 9 \mathrm{mix}$. In the case of $\mathrm{RD}$, similar to $\mathrm{CC}$, there were no changes in colony numbers.

And we compared with induction of mutations in each strain, in the case of TA98, DEP showed higher mutation activity than RSC and PSC, regardless of whether the S9 mix was applied or not. In the case of TA100 strain, RSC showed the highest fold change in UFPs, regardless of the S9 mix. In strain TA1535, only DEP showed a concentration-dependent response in the absence of the $\mathrm{S} 9 \mathrm{mix}$, but in the presence of the S9 mix, we found that RSC, PSC, and TD showed an increase in reverse mutation activity. The fold change in TD, particularly, was higher than that of DEP. Lastly, in the case of strain TA1537, results were similar tendency to those with TA98, which also has a frameshift mutation.
Relative mutagenicity of UFPs with a comparison of specific activity. Specific activity was measured as revertant colony numbers based on total particulate matters (TPM) content $\mathrm{mg}$ (revertants/mg), which was calculated from a slope on the initial concentration range (TPM/plate) that showed concentration dependence curve. Relative genotoxicity was based on DEP, which specific activity showed the highest activity, it expressed as the relative toxicity with other particulate matters as a percentage (Table 4). Therefore, we could compare with levels of activity of each particulate matters, as well as metabolism, using specific activity and relative genotoxicity. DEP in the absence of the S9 mix showed higher specific activity than that of DEP in the presence of the S9 mix at all strains, and also appeared highest specific activities among UFPs.

In case of TA100 as base-pair substitution mutation strain, only biomass combustion (RSC, PSC) showed specific activity, both of samples appeared higher activities at $-\mathrm{S} 9$ mix than $+\mathrm{S} 9$ mix condition. But when compare for relative mutagenicity with DEP, the biomass UFPs had 
Table 4. Specific activity (revertants of $\mathrm{mg}$ ) of Salmonella tester strains following exposure to ultra-fine particles and relative genotoxicity compare with DEP

\begin{tabular}{|c|c|c|c|c|}
\hline Sample $^{a}$ & $\begin{array}{l}\text { Specific activity }+ \text { S9 } \\
\text { (Revertants/mg) }\end{array}$ & $\begin{array}{l}\text { Relative mutagenicity } \\
\qquad(\% \text { of DEP })\end{array}$ & $\begin{array}{l}\text { Specific activity -S9 } \\
\text { (Revertants/mg) }\end{array}$ & $\begin{array}{l}\text { Relative mutagenicity } \\
\text { ( } \% \text { of DEP) }\end{array}$ \\
\hline \multicolumn{5}{|l|}{ TA100 } \\
\hline DEP & $28965 \pm 472$ & 100 & $46958 \pm 5$ & 100 \\
\hline RSC & $1280 \pm 1$ & 4.42 & $1718 \pm 34$ & 0.04 \\
\hline PSC & $1135 \pm 60$ & 3.92 & $1584 \pm 30$ & 0.03 \\
\hline $\mathrm{CC}$ & \multicolumn{2}{|c|}{ Non toxicity up to $200 \mu \mathrm{g} /$ plate } & \multicolumn{2}{|c|}{ Non toxicity up to $200 \mu \mathrm{g} /$ plate } \\
\hline TD & \multicolumn{2}{|c|}{ Non toxicity up to $1,000 \mu \mathrm{g} /$ plate } & \multicolumn{2}{|c|}{ Non toxicity up to $1,000 \mu \mathrm{g} /$ plate } \\
\hline $\mathrm{RD}$ & \multicolumn{2}{|c|}{ Non toxicity up to $300 \mu \mathrm{g} /$ plate } & \multicolumn{2}{|c|}{ Non toxicity up to $300 \mu \mathrm{g} /$ plate } \\
\hline \multicolumn{5}{|l|}{ TA1535 } \\
\hline DEP & $1291 \pm 213$ & 100 & $1528 \pm 145$ & 100 \\
\hline RSC & $28 \pm 2$ & 2.17 & $20 \pm 0$ & 1.31 \\
\hline PSC & $102 \pm 2$ & 7.9 & \multicolumn{2}{|c|}{ Non toxicity up to $100 \mu \mathrm{g} /$ plate } \\
\hline $\mathrm{CC}$ & \multicolumn{2}{|c|}{ Non toxicity up to $200 \mu \mathrm{g} /$ plate } & \multicolumn{2}{|c|}{ Non toxicity up to $200 \mu \mathrm{g} /$ plate } \\
\hline TD & $26 \pm 0$ & 2.0 & $13 \pm 2$ & 0.85 \\
\hline $\mathrm{RD}$ & \multicolumn{2}{|c|}{ Non toxicity up to $300 \mu \mathrm{g} /$ plate } & \multicolumn{2}{|c|}{ Non toxicity up to $300 \mu \mathrm{g} /$ plate } \\
\hline \multicolumn{5}{|l|}{ TA98 } \\
\hline DEP & $43789 \pm 4$ & 100 & $73251 \pm 190$ & 100 \\
\hline $\mathrm{RSC}$ & $1442 \pm 1$ & 3.29 & $618 \pm 2$ & 0.84 \\
\hline PSC & $997 \pm 15$ & 2.28 & $473 \pm 6$ & 0.65 \\
\hline $\mathrm{CC}$ & \multicolumn{2}{|c|}{ Non toxicity up to $200 \mu \mathrm{g} /$ plate } & \multicolumn{2}{|c|}{ Non toxicity up to $200 \mu \mathrm{g} /$ plate } \\
\hline TD & \multicolumn{2}{|c|}{ Non toxicity up to $1,000 \mu \mathrm{g} /$ plate } & \multicolumn{2}{|c|}{ Non toxicity up to $1,000 \mu \mathrm{g} /$ plate } \\
\hline $\mathrm{RD}$ & \multicolumn{2}{|c|}{ Non toxicity up to $300 \mu \mathrm{g} /$ plate } & \multicolumn{2}{|c|}{ Non toxicity up to $300 \mu \mathrm{g} /$ plate } \\
\hline \multicolumn{5}{|l|}{ TA1537 } \\
\hline DEP & $8840 \pm 48$ & 100 & $12368 \pm 9$ & 100 \\
\hline $\mathrm{RSC}$ & $196 \pm 5$ & 2.23 & $77 \pm 4$ & 0.62 \\
\hline PSC & $189 \pm 4$ & 2.99 & $70 \pm 1$ & 0.57 \\
\hline $\mathrm{CC}$ & \multicolumn{2}{|c|}{ Non toxicity up to $200 \mu \mathrm{g} /$ plate } & \multicolumn{2}{|c|}{ Non toxicity up to $200 \mu \mathrm{g} /$ plate } \\
\hline TD & $46 \pm 4$ & 0.52 & $30 \pm 1$ & 0.24 \\
\hline $\mathrm{RD}$ & \multicolumn{2}{|c|}{ Non toxicity up to $300 \mu \mathrm{g} /$ plate } & \multicolumn{2}{|c|}{ Non toxicity up to $300 \mu \mathrm{g} /$ plate } \\
\hline
\end{tabular}

${ }^{\text {a Refer to Table } 1 .}$

higher relative mutagenicity in the presence of the $\mathrm{S} 9 \mathrm{mix}$. In case of TA1535 as base-pair substitution mutation strain, Biomass UFPs had higher activity and relative variability under $+\mathrm{S} 9$ mix condition. Especially, TD showed mutagenicity at TA 1535 regardless of whether the S9 mix. In case of TA 98 as frameshift mutation strain, biomass UFPs with S9 mix had higher specific activity and relative mutagenicity than without $\mathrm{S} 9$ mix. Lastly, in case of TA1537 as frameshift mutation strains, it appeared similar tendencies with TA1535 strain. However, in case of $\mathrm{CC}$ and RD did not show any specific activity and relative mutagenicity at all strain.

\section{DISSCUSION}

In this study, we carried out a reverse mutation test to determine genotoxic differences between DEP and five UFPs, which were obtained from fine particles. Normally, complex mixtures of the above samples are identified as polycyclic organic matter (POM). POM is largely divided into PAHs, substituted aromatic hydrocarbons (SAHs), and heterocyclic aromatic compounds (HCAs). The induced POM from these complex mixtures have shown mutagenicity and carcinogenicity (22). The Ames test would better predict carcinogenesis than various other in vitro shortterm genotoxicity assays, and it can be performed as quickly and easily as other genotoxicity tests (23). Meanwhile, some test materials only show mutagenicity after metabolism in the human body. In this test, most materials show mutagenicity with or without metabolic activity, whereas some show mutation activity only under certain conditions. Microorganisms lack the specific metabolism of mammals. Therefore, to determine mutagenicity with metabolism, we added a metabolically active enzyme extracted from livers. Therefore, the reverse mutation test using microorganisms was conducted with or without metabolic activation.

In this study, DEP showed the highest specific activity among various tested particulate matters. DEP is that the particles in diesel exhaust are composed of center core of 
elemental carbon and absorbed organic and inorganic compounds, it contains PMs of various sizes (24). The DEP generated from automobile diesel engine was tested in this test for relative comparisons, not used standard reference material (SRM) of DEPs, such as SRM 2975. Because, the many mutagenicity studies of SRM 2975 have been studied and it was generated from forklift diesel engine, but there was little study of mutagenicity to DEP from generated from automobile diesel engine (25-27). Moreover, its DEP is a common occurrence around us, a continuous increment of diesel-engine cars has increased the accumulation of DEP in atmosphere of urban arears $(26,28)$. So, we selected DEP generated from automobile diesel engine. The maximum number of revertant colony was 29.6 times more than the number of spontaneous revertants in strain TA98 without the S9 mix. DeMarini et al. confirmed that the mutagenicity of DEP caused by nitroarenes and aromatic amines by using TA98, TA98NR, and TA98/1,8-DNP6 strains, the DEP was same type condition with our DEP (29). In strains TA100 and TA1535, both with base-pair substitution mutations, an increased number of revertant colonies were also observed. In fact, PAHs, specifically $\mathrm{B}[\alpha] \mathrm{P}$, induce base substitution mutations are commonly detected in lung cancers induced by PAHs (28). Therefore, these results were thought that the PAHs, nitroarenes and aromatic amines affected mainly the mutations. Table 1, supports this fact that the PAH/OC percentage was high among samples. DEP showed the highest activity level of all the particulate matters. This means that even a low concentration of DEP may be more mutagenic activity than higher doses of other UFPs. In addition, when we consider that there was a higher level of mutation activity in the absence of the S9 mix than in its presence, DEP itself showed stronger mutation ability than that with metabolic activation.

RSC induced increased revertant colonies in all strains, with and without the S9 mix, except for TA1535 strain with the S9 mix. And in Table 4, RSC generally appeared specific activity and relative mutagenicity followed by DEP. RSC is a biomass, and ordinary biomass is a complex mixture of particles, semi-volatile materials, and gas. The primary biomass compounds largely comprise inorganic compounds (e.g., ammonia and nitric oxide), hydrocarbons (e.g., PAHs and aromatic amines), other organic compound (e.g., carboxylic acids and methylated phenolic compounds), and metals (28). Rice is cultivated ecumenically and is the most popular crop in Asia (29). A common practice in many parts of the world today, emission from field burning of rice residue has potential effects on air quality, atmosphere and climate. Biomass burning spreads the most compounds into the atmosphere, including carcinogenic/mutagenic compounds, e.g., PAHs. Actually, the comparison test was performed by PAHs amounts between burning season of rice and non-burning season.
The PAHs contents was absolutely higher burning season than non-burning season, when the rice straw was burned in hood of laboratory, the significant components were measured with including OC, ions, levoglucosan, HCAs and PAHs $(30,31)$. Also the RSC had very various particle sizes matters with containing PAHs (32). Nevertheless, the mutagenicity of UFP in RSC has not been studied yet. When compared with the results shown in Table 1, we speculate that mutations were caused by two main factors: first, organic compounds in RSC, and second, a single particular compound that showed higher amounts of PAHs than PSC (e.g., B $[\alpha] \mathrm{P}$ and Benzo[ $\alpha]$ anthracene). Actually the detailed compounds in PHAs was not written, RSC had contents of two compounds which be known as mutagenicity more than PSC. Therefore, the result of RSC seems that RSC mainly induced mutations at a hotspot site consisting and a base-pair substitution by HCAs, $\mathrm{B}[\alpha] \mathrm{P}$ of PAHs or organic carbons. PSC is called as biomass combustion like RSC, PSC is also burned for purposes like rice and have a lot of influence on the atmosphere (33). At the previous studies, the correlation was reported between PSC and PAHs, and the mutagenicity of wood or wood pellet combustions were studied $(34,35)$. But the mutagenicity test is not progressed yet with UFP of PSC. The results of PSC testing overall showed lower levels of specific activity than those of RSC. The reason for this difference may be that the organic carbon level was relatively lower specific act in PSC than RSC, as shown in Table 1. However, in contrast with DEP, PSC showed mostly higher fold changes with the $\mathrm{S} 9 \mathrm{mix}$ than without the S9 mix, signifying that the metabolomes of PAHs and HCAs protein pyrolysate were strongly mutagenic.

In the case of $\mathrm{CC}$, no increase in colony numbers was observed, relative to that of the control. This contrasts with a previous reports showing that complex mixtures produced from coal tar generate virulent compounds (e.g., PAHs) that are carcinogenesis and mutagenicity (36). When compare with previous studies, the differences were observed with combustion and collection conditions, followed by contents of PAHs (37). As shown in Table 1, CC has less organic compound and PAH contents than the other UFPs. The cause of these low contents and toxicity is considered that PAHs decompose in the high combustion temperature $\left(1,100^{\circ} \mathrm{C}\right)$ during collection process, or mutagens were segregated and decomposed by regenerating process to obtain PM2.5. A previous report showed that the composition of compounds in coal changed according to combustion temperature and pressure (37). Therefore, we need to consider modifications of experimental methods, such as altering the combustion temperature and filter collection technique. Lastly, general dust is a term that refers to small particles of ambient materials in sedimentary environments (38). Among various types of dust, $\mathrm{RD}$ is a complex mixture consisting of organic compounds 
that include PAHs and potentially toxic contents, e.g., vehicle motor exhaust particles, tire particles, leaked particles of oil and lubricant from vehicles, and eroded road surfaces and cigarette ash. TD is concentrated particles related to vehicles (39-41). However, we only observed minimal mutation activity when testing TD with diameters less than $2.5 \mu \mathrm{M}$ in TA1535 and TA1537 strains, which showed increased revertant colonies with the S9 mix, and without the S9 mix, TA1535 appeared reverse activity with the S9 mix. Strains TA1535 and TA1537 have frameshift and base-pair substitution mutations, and these strains do not have the pKM101 plasmid. This is considered as optional mutation appearance by metabolome of compounds in TD that was induced selectively in strains TA1535 and TA1537 which do not have pKM101 as plasmid. This is thought as the under $2.5 \mu \mathrm{M}$ diameter small particles generated by vehicle in tunnel area affected on the results.

In this study, we compared mutagenicity, with or without metabolic activation, using several kinds of UFPs. In various air pollutant particulate matters, PAHs and organic compounds such as aromatic amines and HCAs are primary factors in mutagenicity. Among the collected particulate matters, DEP showed the highest level of mutagenic activity, even at low concentrations. Additional toxicity assessments, including considerations of the compound composition, cell toxicity, and oxidative stress, are needed to identify ways to reduce the mutagenicity of particulate matters and inform people the dangerousness and seriousness of UFPs.

\section{ACKNOWLEDGMENTS}

We would like to appreciate completion of this manuscript to Dr Han Jae Shin (KT\&G Research Institute) and thank Prof Ki Hong Park (Gwangju Institute of Science and Technology) to helped collection and analysis of samples. The author received the financial support of the Social Problem Solving Technology Developmemt Project (2014M3C8A5030612) for research.

Received January 30, 2018; Revised March 18, 2018; Accepted March 19, 2018

\section{REFERENCES}

1. Weidemann, E., Andersson, P.L., Bidleman, T., Boman, C., Carlin, D.J., Collina, E., Cormier, S.A., Gouveia-Figueira, S.C., Gullett, B.K., Johansson, C., Lucas, D., Lundin, L., Lundstedt, S., Marklund, S., Nording, M.L., Ortuno, N., Sallam, A.A., Schmidt, F.M. and Jansson, S. (2016) 14th congress of combustion by-products and their health effectsorigin, fate, and health effects of combustion-related air pollutants in the coming era of bio-based energy sources. Environ. Sci. Pollut. Res. Int., 23, 8141-8159.
2. Brunekreef, B. and Holgate, S.T. (2002) Air pollution and health. Lancet, 360, 1233-1242.

3. Kim, K.H., Kabir, E. and Kabir, S. (2015) A review on the human health impact of airborne particulate matter. Environ. Int., 74, 136-143.

4. Samet, J.M., Dominici, F., Curriero, F.C., Coursac, I. and Zeger, S.L. (2000) Fine particulate air pollution and mortality in 20 U.S. cities, 1987-1994. N. Engl. J. Med., 343, 17421749.

5. Yang, W. and Omaye, S.T. (2009) Air pollutants, oxidative stress and human health. Mutat. Res., 674, 45-54.

6. Fang, T., Verma, V., Guo, H., King, L., Edgerton, E. and Weber, R.J. (2014) A semi-automated system for quantifying the oxidative potential of ambient particles in aqueous extracts using the dithiothreitol (DTT) assay: results from the Southeastern Center for Air Pollution and Epidemiology (SCAPE). Atmos. Meas. Tech., 8, 471-482.

7. Valavanidis, A., Vlachogianni, T., Fiotakis, K. and Loridas, S. (2013) Pulmonary oxidative stress, inflammation and cancer: respirable particulate matter, fibrous dusts and ozone as major causes of lung carcinogenesis through reactive oxygen species mechanisms. Int. J. Environ. Res. Public Health, 10, 3886-3907.

8. Pope, C.A., 3rd, Burnett, R.T., Thun, M.J., Calle, E.E., Krewski, D., Ito, K. and Thurston, G.D. (2002) Lung cancer, cardiopulmonary mortality, and long-term exposure to fine particulate air pollution. Jama, 287, 1132-1141.

9. Cao, J., Xu, H., Xu, Q., Chen, B. and Kan, H. (2012) Fine particulate matter constituents and cardiopulmonary mortality in a heavily polluted Chinese city. Environ. Health Perspect., 120, 373-378.

10. Reid, J.S., Koppmann, R., Eck, T.F. and Eleuterio, D.P. (2005) A review of biomass burning emissions, part II: intensive physical properties of biomass burning particles. Atmos. Chem. Phys., 5, 799-825.

11. Ema, M., Naya, M., Horimoto, M. and Kato, H. (2013) Developmental toxicity of diesel exhaust: a review of studies in experimental animals. Reprod. Toxicol., 42, 1-17.

12. Shen, G. (2017) Mutagenicity of particle emissions from solid fuel cookstoves: a literature review and research perspective. Environ. Res., 156, 761-769.

13. Matzenbacher, C.A., Garcia, A.L.H., dos Santos, M.S., Nicolau, C.C., Premoli, S., Corrêa, D.S., de Souza, C.T., Niekraszewicz, L., Dias, J.F., Delgado, T.V., Kalkreuth, W., Grivicich, I. and da Silva, J. (2017) DNA damage induced by coal dust, fly and bottom ash from coal combustion evaluated using the micronucleus test and comet assay in vitro. $J$. Hazard. Mater, 324, 781-788.

14. Melki, P.N., Ledoux, F., Aouad, S., Billet, S., El Khoury, B., Landkocz, Y., Abdel-Massih, R.M. and Courcot, D. (2017) Physicochemical characteristics, mutagenicity and genotoxicity of airborne particles under industrial and rural influences in Northern Lebanon. Environ. Sci. Pollut. Res. Int., 24, 18782-18797.

15. Singh, P., DeMarini, D.M., Dick, C.A., Tabor, D.G., Ryan, J.V., Linak, W.P., Kobayashi, T. and Gilmour, M.I. (2004) Sample characterization of automobile and forklift diesel exhaust particles and comparative pulmonary toxicity in mice. Environ. Health Perspect., 112, 820-825. 
16. Wu, D., Zhang, F., Lou, W., Li, D. and Chen, J. (2017) Chemical characterization and toxicity assessment of fine particulate matters emitted from the combustion of petrol and diesel fuels. Sci. Total Environ., 605-606, 172-179.

17. Maron, D.M. and Ames, B.N. (1983) Revised methods for the Salmonella mutagenicity test. Mutat. Res., 113, 173-215.

18. Claxton, L.D., Umbuzeiro Gde, A. and DeMarini, D.M. (2010) The Salmonella mutagenicity assay: the stethoscope of genetic toxicology for the 21st century. Environ. Health Perspect., 118, 1515-1522.

19. McDonald, J.D., Barr, E.B., White, R.K., Chow, J.C., Schauer, J.J., Zielinska, B. and Grosjean, E. (2004) Generation and characterization of four dilutions of diesel engine exhaust for a subchronic inhalation study. Environ. Sci. Technol., 38, 2513-2522.

20. DeMarini, D.M. (2004) Genotoxicity of tobacco smoke and tobacco smoke condensate: a review. Mutat. Res., 567, 447474.

21. Shin, H.-J., Cho, H.G., Park, C.K., Park, K.H. and Lim, H.B. (2017) Comparative in vitro biological toxicity of four kinds of air pollution particles. Toxicol. Res., 33, 305-313.

22. Lewtas, J. (1993) Complex mixtures of air pollutants: characterizing the cancer risk of polycyclic organic matter. Environ. Health Perspect., 100, 211-218.

23. Snyder, R.D. and Green, J.W. (2001) A review of the genotoxicity of marketed pharmaceuticals. Mutat. Res., 488, 151169.

24. Claxton, L.D., Creason, J., Leroux, B., Agurell, E., Bagley, S., Bryant, D.W., Courtois, Y.A., Douglas, G., Clare, C.B., Goto, S., Quillardet, P., Jagannath, D.R., Kataoka, K., Mohn, G., Nielsen, P.A., Ong, T., Pederson, T.C., Shimizu, H., Nylund, L., Tokiwa, H., Vink, G.J., Wang, Y. and Warshawsky, D. (1992) Results of the IPCS collaborative study on complex mixtures. Mutat. Res., 276, 23-32.

25. Hughes, T.J., Lewtas, J. and Claxton, L.D. (1997) Development of a standard reference material for diesel mutagenicity in the Salmonella plate incorporation assay. Mutat. Res., 391, 243-258.

26. McClellan, R.O., Brooks, A.L., Cuddihy, R.G., Jones, R.K., Mauderly, J.L. and Wolff, R.K. (1982) Inhalation toxicology of diesel exhaust particles. Dev. Toxicol. Environ. Sci., 10, 99-120.

27. Krause, G., Garganta, F., Vrieling, H. and Scherer, G. (1999) Spontaneous and chemically induced point mutations in HPRT cDNA of the metabolically competent human lymphoblastoid cell line, MCL-5. Mutat. Res., 431, 417-428.

28. Lim, W.Y. and Seow, A. (2012) Biomass fuels and lung cancer. Respirology, 17, 20-31.

29. Kadam, K.L., Forrest, L.H. and Jacobson, W.A. (2000) Rice straw as a lignocellulosic resource: collection, processing, transportation, and environmental aspects. Biomass Bioenergy, 18, 369-389.

30. Andreae, M.O. and Merlet, P. (2001) Emission of trace gases and aerosols from biomass burning. Global Biogeochem. Cycles, 15, 955-966.

31. Oanh, N.T., Bich, T.L., Tipayarom, D., Manadhar, B.R., Prapat, P., Simpson, C.D. and Liu, L.J. (2011) Characterization of particulate matter emission from open burning of fice straw. Atmos. Environ., 45, 493-502.

32. Yang, H.-H., Tsai, C.-H., Chao, M.-R., Su, Y.-L. and Chien, S.-M. (2006) Source identification and size distribution of atmospheric polycyclic aromatic hydrocarbons during rice straw burning period. Atmos. Environ., 40, 1266-1274.

33. Pope, C.A. (2000) Review: epidemiological basis for particulate air pollution health standards. Aerosol Sci. Technol., 32, 4-14.

34. Cohn, C.A., Lemieux, C.L., Long, A.S., Kystol, J., Vogel, U., White, P.A. and Madsen, A.M. (2011) Physical-chemical and microbiological characterization, and mutagenic activity of airborne PM sampled in a biomass-fueled electrical production facility. Environ. Mol. Mutagen., 52, 319-330.

35. Chakraborty, R. and Mukherjee, A. (2009) Mutagenicity and genotoxicity of coal fly ash water leachate. Ecotoxicol. Environ. Saf., 72, 838-842.

36. Liu, G., Niu, Z., Van Niekerk, D., Xue, J. and Zheng, L. (2008) Polycyclic aromatic hydrocarbons (PAHs) from coal combustion: emissions, analysis, and toxicology. Rev. Environ. Contam. Toxicol., 192, 1-28.

37. Cai, H.Y., Güell, A.J., Chatzakis, I.N., Lim, J.Y., Dugwell, D.R. and Kandiyoti, R. (1996) Combustion reactivity and morphological change in coal chars: Effect of pyrolysis temperature, heating rate and pressure. Fuel, 75, 15-24.

38. Lorenzi, D., Entwistle, J.A., Cave, M. and Dean, J.R. (2011) Determination of polycyclic aromatic hydrocarbons in urban street dust: Implications for human health. Chemosphere, 83, 970-977.

39. Dong, T.T. and Lee, B.K. (2009) Characteristics, toxicity, and source apportionment of polycylic aromatic hydrocarbons (PAHs) in road dust of Ulsan, Korea. Chemosphere, 74, 1245-1253.

40. Mostafa, A.R., Hegazi, A.H., El-Gayar, M.S. and Andersson, J.T. (2009) Source characterization and the environmental impact of urban street dusts from Egypt based on hydrocarbon distributions. Fuel, 88, 95-104.

41. Zhang, W., Zhang, S., Wan, C., Yue, D., Ye, Y. and Wang, X. (2008) Source diagnostics of polycyclic aromatic hydrocarbons in urban road runoff, dust, rain and canopy throughfall. Environ. Pollut., 153, 594-601. 